\title{
As qualidades ecológicas das redes indígenas no Brasil
}

The ecological qualities of indigenous networks in Brazil

Las cualidades ecológicas de las redes indígenas en Brasil

\section{Eliete da Silva PEREIRA}

Centro Internacional de Pesquisa Atopos-ECA/USP

elisilva70@gmail.com

\section{Massimo DI FELICE}

Universidade de São Paulo

massimo@usp.br

Chasqui. Revista Latinoamericana de Comunicación

N.o 147, agosto-noviembre 2021 (Sección Monográfico, pp. 201-220)

ISSN 1390-1079 / e-ISSN 1390-924X

Ecuador: CIESPAL

Recibido: 25-03-2021 / Aprobado: 10-07-2021 


\title{
Resumo
}

Este artigo trata do processo da formação de redes sociotécnicas indígenas no Brasil a partir da análise de três experiências: a Rede Povos da Floresta, a Rede Indígena de Memória e Museologia Social e a Rede CineFlecha. Por meio de uma pesquisa qualitativa de cunho teórico investigou-se as arquiteturas informativas destas três redes, analisando suas especificidades hipertextuais, na qual verificou-se, além de uma intensa atuação comunicativa, suas qualidades cosmopolíticas e ecológicas. A observação e o estudo dessas redes exprimem um particular tipo de interação que vai além da dimensão técnica e social abrangendo a esfera ecológica, ambiental e cosmológica.

Palavras-chave: comunicação digital, digitalização, redes indígenas, povos indígenas, redes sociotécnicas

\begin{abstract}
This article deals with the process of forming indigenous sociotechnical networks in Brazil based on the analysis of three experiences: the Network of Peoples of the Forest, the Network of Indigenous Memory and Social Museology and the Network of CineFlecha. Through a qualitative research of a theoretical nature, the informative architectures of these three networks were investigated, analyzing their hypertextual specificities, in which, in addition to an intense communicative performance, their cosmopolitical and ecological qualities were verified. The observation and study of these networks express a particular type of interaction that goes beyond the technical and social dimension, encompassing the ecological, environmental and cosmological spheres
\end{abstract}

Key words: digital communication, digitization, indigenous networks, indigenous peoples, socio-technical networks

\section{Resumen}

Este artículo aborda el proceso de formación de redes sociotécnicas indígenas en Brasil a partir del análisis de tres experiencias: la Red de los Pueblos dela Floresta, la Red Indígena de Memória y Museología Social y la Red CineFlecha. A través de una investigación cualitativa de carácter teórico, se investigaron las arquitecturas informativas de estas tres redes, analizando sus especificidades hipertextuales, en las que, además de una intensa actuación comunicativa, se verificaron sus cualidades cosmopolíticas y ecológicas. La observación y el estudio de estas redes expresan un tipo particular de interacción que va más allá de la dimensión técnica y social, abarcando la esfera ecológica, ambiental y cosmológica.

Palabras clave: comunicación digital, digitalización, redes indígenas, pueblos indígenas, redes sociotécnicas 


\section{Introdução}

Nas últimas décadas os povos indígenas brasileiros vêm incorporando ${ }^{1}$ as tecnologias digitais em seu cotidiano, promovendo uma atuação comunicativa nas redes digitais que, enquanto condizente com a já existente dimensão reticular das relações entre estes povos, exprime um particular tipo de complexificação que definimos como uma forma de ecologia da comunicação ${ }^{2}$ digital ameríndia. O aparecimento da Internet e dos dispositivos de conexão, seus aspectos pervasivos e ubíquos difundidos em escala global, tornaram-se os vetores do processo de digitalização do qual territórios, pessoas e coisas se (info) materializam (Di Felice, 2017). Ao fazerem parte desse contexto informacional, os povos indígenas experimentam a complexificação das suas práticas comunicativas, primordialmente conectivas entre os seus diversos planos cosmológicos (visíveis e invisíveis).

No Brasil, tal processo de digitalização ocorreu com maior abrangência através das iniciativas de organizações não-governamentais (ONGs) e de organizações governamentais executoras de políticas públicas de inclusão digital, sobretudo, pelo Programa GESAC ${ }^{3}$ e Pontos de Cultura Indígena ${ }^{4}$. Estudos sobre os usos indígenas da internet (Pereira, 2007, 2012; Morales, 2008; Renesse, 2012; Klein, 2013; Franco, 2019) apontam para uma inserção dessas populações na cultura digital. Embora não existam estatísticas oficiais mais detalhadas sobre o acesso indígena à Internet e quanto são as aldeias que possuem conexão, experiências significativas apontam o processo inovador de práticas conectivas de relações com os Outros, de reflexividade cultural (Klein, 2013), de tradução e visibilidade de saberes e culturas locais (Pereira, 2020).

No intuito de apresentar um panorama dessa atuação, este artigo trata do processo de digitalização como potencializador da formação de redes sociotécnicas indígenas no Brasil, a partir da análise de três experiências exemplares: a histórica Rede Povos da Floresta, a Rede de Memória Indígena e

1 O termo "incorporação" é um contraponto diferencial da ideia instrumental de "apropriação midiática", inspirado na análise das redes xamânicas e sua contribuição para uma ideia ecológica de comunicação digital de Fernanda Moreira (2014).

2 O termo "ecologia da comunicação" foi debatido por Moles (1975 apud Mattelart 2003) a partir de um modelo matemático de interação entre espécies diferentes de um dado campo. Santaella (2010) também chama de "ecologia pluralista da comunicação" tomando a 'ecologia' como metáfora eficaz para se pensar as novas relações propiciadas pela revolução digital (a emergência das redes digitais e das mídias locativas) nas esferas da vida social e psíquica. Di Felice (2017) associa à ecologia da comunicação a alteração realizada pelas tecnologias digitais conectivas no espaço e na ideia de "ação".

3 Criado em 2002, o programa GESAC (Governo eletrônico de atendimento ao cidadão) oferece conexão de internet via satélite e terrestre a telecentros em várias comunidades em estado de vulnerabilidade social. Segundo Cristiano Mariotto (2014), o GESAC até 2014 fornecia acesso à internet a 45 aldeias em todo o país.

4 O Programa Cultura Viva iniciado em 2004 do Ministério da Cultura teve como principal ação o fomento dos Pontos de Cultura, que são iniciativas desenvolvidas formal ou informalmente organizadas pela sociedade civil. Com o atual governo do Presidente Jair M. Bolsonaro o futuro de tal Programa é completamente incerto. 
Museologia Social e a recém-lançada Rede CineFlecha, no contexto da pandemia de Convid-19.

\section{Marco teórico}

Os pressupostos epistêmicos adotados neste estudo envolvem diretamente o estudo das especificidades ecológicas e conectivas das redes digitais indígenas. A análise de tal temática foi interpretada através das contribuições teóricas de três áreas temáticas: 1. a complexidade reticular, 2 . A dimensão conectiva das redes digitais e 3. a morfologia social e as redes relacionais dos povos indígenas no Brasil.

A introdução à teoria da complexidade reticular, além dos clássicos dos estudos de redes (Granovetter, 1973), foi guiada pela complexidade das arquiteturas relacionais dos povos indígenas (Pereira, 2012; 2013; Moreira, 2014) e pela contribuição da teoria da complexidade elaborada por Edgar Morin (2001), pelas quais identificamos nestes estudos as dimensões dialógicas, recursivas e hologramáticas indicativas de uma arquitetura informacional constitutiva da atuação comunicativa indígena contemporânea. Da mesma forma, as qualidades emergentes, agregativas e sociotécnicas das redes indígenas estudadas vão ao encontro das contribuições de J. Law, M. Callon e B. Latour (2012), sobretudo, dada a concepção da morfologia social indígena incluir as dimensões humanas e não humanas presentes em suas cosmologias.

As atuações comunicativas reticulares envolvem espaços glocalmente5 localizados e atravessados por sistemas comunicativos interativos de suas arquiteturas digitais (redes, sites, blogs, portais etc.), que se manifestam enquanto "formas comunicativas do habitar", dada a simbiose entre sujeitos, culturas, mídias digitais e território (Di Felice, 2009). Portanto, são expressões dos dinamismos comunicativos associativos dos seus atores-redes6 (Latour, 2004, 2012); das culturas e de seus territórios expandidos, situados na "tríade simbiôntica” e de interações recíprocas entre culturas, redes digitais e territórios (Pereira, 2013).

Nos casos analisados das três redes indígenas, há a evidência da especificidade da atuação da ecologia comunicativa própria de cada um destes povos, pela qual não são somente os humanos "comunicam", "agem" e "atuam", mas também os não humanos, o território, o sagrado, as plantas e os animais, enfim, todo o universo pertencente às suas complexas cosmologias. Essas referem-se aos seus universos cosmológicos originários e míticos, pensamentos

5 Referimo-nos ao termo "glocal" - discutido por Roland Robertson (1999) - como sendo mais adequado que o termo "global" para designar as tendências de homogeneização e heterogeneização, aparentemente contrapostas, mas que são complementares e interpenetrantes. Robertson amplia o termo "glocal", apresentado no Oxford Dictionary of New Words, no qual é mencionado como baseado na noção japonesa dochaku, "viver na própria terra", adoção de princípios agrícolas às condições locais.

6 A noção "ator-rede" também se refere àquela elaborada por Bruno Latour (2004), sendo tudo aquilo e aquele que age na rede, humano ou não humano. 
expressivos de visões de mundo e de práticas rituais de interação simbólica e ambiental em diversos planos que formam redes sensíveis e suprassensíveis, presentificadas e incorporadas. É importante considerar que as cosmologias e a morfologia do social indígenas se diferem entre si e são reveladoras de formas de comunicação ecológicas, marcadas pelo processo de heterogênese e transgressões de fronteiras (Moreira, 2014), vide as técnicas xamânicas de comunicação e trânsito entre diferentes espécies (Viveiros de Castro, 2013, Kopenawa \& Albert, 2015)

Com o advento das tecnologias digitais e o processo de digitalização protagonizado por essas populações, essa comunicação com o cosmo se estende aos múltiplos auditórios (indígenas e não indígenas) e se mostra ativa nos contextos políticos interétnicos, de mobilização e defesa de direitos (netativismo indígena), conforme Di Felice \& Pereira (2017) e Franco (2020). Ao ser digitalizada, a ecologia da comunicação indígena e a morfologia de seu social incorporam as interações já existentes entre as diversas entidades pertencentes ao universo simbólico e ecológico de cada povo, estendendo-o ao ecossistema informativo das redes digitais em suas diversas linguagens (hipertextuais, sonoras, audiovisuais).

Dessa forma, as apropriações, incorporações e interações com as tecnologias e as linguagens midiáticas por parte desses povos evocam uma "cosmopolítica ameríndia" (Stengers, 2011; Sztutman, 2012), indicadora de uma interação reticular, associada ao seu contexto de relações e de agências múltiplas (presentes em suas cosmologias). É, portanto, por meio deste modo de "comunicar", "transitar", "atuar" em redes no cosmo, onde repercutem a contínua preocupação com as suas "terras", o lugar de existência cultural, corpórea e extra-corporea de todos os seres que o compõe, bem como é por meio da comunicação com esse cosmo e colocando- se "em relação" com as suas diversas entidades, que cada povo se presentifica atualmente nas redes digitais.

A análise da dimensão conectiva foi elaborada a partir das contribuições de alguns estudos relacionado às últimas gerações de redes (Accoto, 2020; Floridi, 2014; Lemos, 2010; Santaella, 2010) que mostram a dimensão conectiva e ecológica das interações em ambientes digitais.

Compreende-se por redes digitais aqui as diversas arquiteturas interativas de informação (plataforma de informação on-line, seja portal, site, redes sociais) como pontos de acesso, compartilhamento de informações (textuais, imagéticas, audiovisuais) efetivados pelos dispositivos de conectividade (smartphones, computadores, tablets etc.). Portanto, o processo de digitalização e a criação de copresença nas redes digitais exprimem pontos de conectividade com outras redes já existentes, sejam elas ambientais (flora e fauna), cosmológicas e sociais entre humanos e não humanos (hardwares etc.).

Enfim, a terceira área temática referem-se aos estudos sobre as morfologias do social e as complexidades relacionais das redes indígenas no Brasil (Pereira e Di Felice, 2017). As primeiras experiências indígenas brasileiras de produção 
de arquiteturas interativas na Internet registram-se a partir de $2001 \mathrm{em}$ blogs e sites (Pereira, 2012). A primeira arquitetura de rede digital registrada no Brasil foi o Portal da Rede Índios Online, criada em 2004, pela Organização não Governamental Thydewá (em Pankararu, "esperança da terra”), formada por não indígenas e indígenas da região do Nordeste. Com textos, imagens e vídeos publicados pelas sete etnias participantes - Kiriri, Tupinambá, Pataxó Hã-HãHãe, Tumbalalá (Bahia), Xucuru-Kariri, Kariri-Xocó (Alagoas) e Pankararu (Pernambuco) - a Rede Índios Online foi pioneira na atuação indígena nas redes digitais, conectando essas comunidades ao Portal e ao chat, iniciativa largamente reconhecida, premiada e investigada (Pereira, 2012).

A Rede Índios Online teve um papel fundamental na difusão das demandas das etnias situadas no Nordeste, até então consideradas "desaparecidas" pelos pesquisadores, e protagonistas das retomadas dos antigos territórios indígenas na região, período descrito pelos antropólogos de "etnogênese" (Oliveira Filho, 1999). Além disso, a Índios Online marcou uma geração de comunicadores indígenas, entre os quais, Anápuáka Tupinambá, fundador da "Rádio Yandê" - a primeira Rádio Web Indígena do país, criada em 2013.

Nos últimos anos, a atuação das redes indígenas nas e com as redes digitais multiplicaram-se encontrando diversas modalidades. Sobretudo, por meio da conectividade dos territórios gerada pelas redes de última geração (Internet of things, sensores etc), as redes indígenas expandiram-se em direção ao meio ambiente, com ações de monitoramento territorial, a exemplo do Mapa Cultural dos Suruí Paiter (2007) da Terra Indígena Sete de Setembro (no estado de Rondônia) em parceria com o Google Earth (Moreira, 2014; Pereira e Di Felice, 2017), e também em direção ao registro de suas memórias e suas referências culturais, como no caso da mobilização dos Pataxó com o Portal da Cultura Viva Pataxó - Muká Mukaú (2009) (Pereira, 2020).

Este processo de expansão das redes indígenas indica, portanto, a não contraposição no âmbito destas culturas entre a dimensões técnicas, ecológicas e sociais.

\section{Metodologia}

Para a análise, selecionamos três experiências ${ }^{7}$ que se destacam pelas suas especificidades e aplicamos métodos específicos para cada uma delas:a primeira, a Rede Povos da Floresta, criada em 2003, não mais ativa, mas que deixou um legado e foi fundamental para a criação da política pública cultural conhecida como Pontos de Cultura Indígena (2007-2016); a segunda é a Rede Indígena de Memória e Museologia Social, articuladora de uma série de iniciativas de registro e espaços de memórias protagonizados por indígenas; a terceira e

7 Tais experiências estudadas se inserem dentro das atividades de pesquisa dos autores, relacionadas à linha de pesquisa "Tekó: a digitalização dos saberes locais" do Centro Internacional de Pesquisa Atopos (ECA-USP). 
última é uma rede emergente criada em 2020 no contexto da pandemia, a Rede CineFlecha, uma plataforma audiovisual de produções indígenas.

Quanto à Rede Povos da Floresta (RPF) analisaram-se as associações dos atores-rede que a constituíram, o site e a página no facebook, entre 2009 e 2011, durante a pesquisa de doutoramento da coautora Eliete S. Pereira, quando foram adotados os procedimentos da etnografia do virtual (Hine, 2010) e da netnografia (Kozinets, 2010): diário de campo, imersão do pesquisador e construção de rotas de navegação (Santaella, 2004). Elegeu-se um dos polos da RPF, o Centro Yorenka Ãtame do Povo Ashaninka no Acre, para a realização da pesquisa etnográfica, em novembro de 2011, com aplicação de entrevistas semiestruturadas com os seus participantes e idealizadores, entre eles, Ailton Krenak ${ }^{8}$. Tais entrevistas foram posteriormente descritas e categorizadas segundo 1) motivo da criação da rede; 2) atuação dos atores (actantes humanos e não humanos) no processo de criação da própria rede; 3) tipo e especificidade da arquitetura de interação incorporada por esses povos.

No caso da Rede Indígena de Memória e Museologia Social analisamos as atas de fundação da Rede, bem como o registro presencial e as entrevistas dos integrantes da rede. A coautora acompanha a articulação da rede desde 2016, a partir de então participou dos Fóruns Nacionais de Museus Indígenas realizados em 2016 e 2017. Além disso, a coautora participa do grupo da Rede no WhatsApp, onde neste aplicativo, os membros da rede compartilham informações sobre diversos temas relacionados à própria constituição da rede e às questões indígenas no país. Essa posição insider na rede (Amaral, 2009) permitiu acompanhar diretamente a formação da rede em seus aspectos comunicativos e de mobilização. Também foi analisada a página no Facebook dessa rede indígena.

Para analisar a Rede CineFlecha, estudamos os conteúdos compartilhados pelos coletivos envolvidos nessa arquitetura de interação e informação e os materiais de divulgação da recém-lançada plataforma audiovisual, criada em 2020, no contexto da pandemia. Nesse sentido, nessa arquitetura, instigamos a própria arquitetura da informação que nos permitiu a compreensão sobre o ato comunicacional (situação de copresença) e que põe a "necessidade de uma reflexão sobre as mediações da comunicação por meio dos computadores e softwares e os códigos compartilhados, sejam eles verbais ou corporais ou outros" (Rifiotis, 2010, p. 21). Pesquisamos, sobretudo, os vídeos compartilhados pelos coletivos participantes da Rede em seus aspectos tecno-imagéticos.

8 Entrevista realizada pelo Messenger do Facebook entre os dias 15 e 16 de novembro de 2011. Em 2016 nos reencontramos em Brasília, conversamos sobre o fim da rede e seu legado. 


\section{Discussão e resultados}

\subsection{Rede Povos da Floresta: pioneirismo e atuação da cosmologia Ashaninka}

A Rede Povos da Floresta nasceu em setembro de 2003 da revitalização da Aliança dos Povos da Floresta, um movimento social e ambiental muito forte no Acre na década de 1980 (Carneiro da Cunha \& Almeida, 2002), que contou com a participação de povos indígenas, ribeirinhos e seringueiros, resultado da liderança de Chico Mendes e da participação de líderes indígenas, entre eles Ailton Krenak.

A história do movimento tem origem no processo de ocupação territorial e na inserção econômica local no contexto mundial. Dois ciclos econômicos de comercialização mundial da borracha (1870-1912; 1943-1945) lançaram a região do Alto Juruá (AC) e de todo o Acre no mapa do comércio internacional. Historicamente essa opção extrativa foi permeada por diversas controvérsias, que envolvem o desenvolvimento da região associado aos interesses nacionais e internacionais e a percepção do extrativismo como economia 'inviável'. Nesse contexto, o movimento dos seringueiros nasce e se fortalece pela capacidade deles de constituírem redes de apoios, extrapolando a própria localidade e ganhando respeito internacional e nacional. Foi um movimento glocal por excelência em virtude de suas alianças. O movimento dos seringueiros e sua aliança com os povos indígenas transformavam-se, assim, num "paradigma do desenvolvimento sustentável com participação popular", um forte "movimento de resistência ecológica" (Almeida, 2004, p. 33).

Após o assassinato de Chico Mendes em dezembro de 1988, a Aliança dos Povos da Floresta foi lançada oficialmente no dia 12 de maio de 1989, em São Paulo, pelos representantes da União das Nações Indígenas e do Conselho Nacional dos Seringueiros, constituindo um marco importante do indigenismo e do ambientalismo acreano, com destaque para a região do Alto Juruá (Pimenta, 2007).

Para José Pimenta (2007, p. 639), a Aliança dos Povos da Floresta "testemunha não apenas a capacidade de resistência das populações indígenas em face das políticas integracionistas e assimilacionistas do Estado, mas também exemplifica a criatividade e o dinamismo das recomposições identitárias contemporâneas", dado uma situação comum de exploração vivido por índios e seringueiros. Contudo, nos anos de 1990, essa articulação histórica foi aos poucos sendo desativada por divergências entre as lideranças indígenas e seringueiras.

Ao atualizar essa mobilização histórica, a Rede Povos da Floresta nasceu da rearticulação dos povos indígenas (principalmente dos Ashaninka, Kontanawa, Kaxinawa), dos ribeirinhos, das populações extrativistas e quilombolas e de organizações não governamentais parceiras, como a Associação de Cultura e Meio Ambiente (Rio de Janeiro) e o Núcleo de Cultura Indígena (Minas Gerais). Eles se uniram com o objetivo de consolidar a rede dessas comunidades 
tradicionais, conectadas por meio das tecnologias digitais de comunicação (internet e sistemas de georreferenciamento com GPS) para a preservação do ambiente, incluindo seus aspectos naturais, culturais e simbólicos.

Conectadas pela internet via satélite, essas comunidades articularam projetos, trocaram informações com seus apoiadores, acionando os órgãos públicos quando da ocorrência de invasões de suas terras, além de terem realizado o registro audiovisual de suas memórias e narrativas, iniciativa que associa seus territórios e culturas à conectividade e às linguagens midiáticas digitais.

Segundo Benki Pianko do povo Ashaninka, "A gente quer aprender toda essa tecnologia que está chegando à nossa aldeia para ter esse mundo de comunicação. Porque para nós é muito importante saber o que está acontecendo lá fora e transmitir o que estamos vivendo aqui também"9.

Ainda que não fosse exclusivamente uma "rede indígena", a participação indígena de Ailton Krenak e do Povo Ashaninka, representado por Benki Pianko e o Centro Yorenka Ãtame, foram fundamentais. Os Ashaninka se destacam pelo nível de engajamento, articulação e presença em sua própria comunidade e seu reconhecido prestígio dentro e fora dela. Essa "supremacia" Ashaninka na RPF deve-se, assim, às especificidades da comunidade Apiwtxa do Rio Amônia, e da família Pianko, de como eles conseguiram reverter para si o contato com os brancos, reinterpretando seus "recursos cosmológicos" (Lessin, 2011), tornando-se os enunciadores do desenvolvimento sustentável local a partir da lógica de desenvolvimento de "projetos" (Pimenta, 2007), em que se considera também os agentes não humanos desse ecossistema.

Os Ashaninkas do Rio Amônia possuem uma predisposição às deslocações e às trocas (ayonpari na língua Ashaninka), uma configuração tradicional reticular "mercuriana", que lhes deu a capacidade de exercer uma diplomacia política voltada à própria autonomia política e cultural ${ }^{10}$. Lessin (2011) refere-se a um "complexo ritualístico voltado à produção de pessoas", ao ritual ${ }^{11}$ do piyaretsi uso da bebida fermentada da madioca, pelo qual reforçam seus laços políticos e culturais entre os pares - e ao ritual do kamparampi (Ayahuasca), capaz de romper o tempo histórico para o ingresso ao tempo mítico de uma humanidade irrestrita ${ }^{12}$. São esses rituais um momento de "produção de pessoas" (Viveiros de Castros, 2006 apud (Lessin, 2011) e de afinidades potenciais de trocas.

9 Disponivel em: http://redepovosdafloresta.org.br/exibePagina.aspx?pag=54\&pagTipo=c. Acesso em: 11 nov. 2011.

10 Não é por acaso que o prefeito atual do município de Marechal Thamaturgo, Isaac Pianko é Ashaninka, eleito em 2020.

11 Referimo-nos ao rito como ação que se repete segundo regras invariáveis, cujo ato não se esgota por sua eficácia, causa ou efeitos. Os rituais dizem respeito ao desenvolvimento do rito. No caso das populações ameríndias da Amazônia, os rituais presentificam o 'tempo mitíco' das suas cosmologias, como explica Lessin (2011).

12 Vale reforçar o significado da Ayahuasca (kamparampi) para a cosmologia xamânica amazônica, bem como Ashaninka, neste excerto de Lessin (2011, p. 113): "Para se pensar a política e a economia externa Ashaninka é necessário levar em conta o mundo espiritual como parte integrante do Cosmos indígena. 
Esse devir diplomático dos Ashaninka está no âmago do Centro Yorenka Ãtame (na língua Ashaninka significa Saberes da Floresta), inaugurado em 2007, idealizado pela aldeia Ashaninka do Rio Amônia - Apiwtxa (Terra Indígena do Kampa). Situado ao lado direito do rio Juruá, na frente do Município de Marechal Thamaturgo (AC), o Yorenka Ãtame foi criado como um espaço de educação, formação, intercâmbio de práticas de manejo sustentável dos recursos da região, integrando com o uso dos sistemas agroflorestais as populações indígenas e não indígenas na recuperação de áreas degradadas. É a expressão máxima de um projeto ousado e pioneiro de desenvolvimento sustentável promovido por uma comunidade indígena brasileira e, portanto, inserido em uma estratégia muito peculiar de cosmopolítica interétnica realizada pelos Ashaninka da aldeia Apiwtxa (Pereira, 2013). Ao somar-se à capacidade de associação e de conectividade de seus membros, o Centro formou um importante "nó" da RPF.

A Rede Povos da Floresta esteve ativa entre 2003 e 2011. Segundo Ailton Krenak, ainda que a RPF não exista mais, até pela obsolescência da tecnologia utilizada na época, ela teve um papel pioneiro e fundamental em semear outras redes conectivas indígenas e, principalmente, contribuiu para a constituição de uma política pública cultural específica para o segmento: os Pontos de Cultura Indígena em 2007.

Quanto ativa, a espacialidade comunicativa da arquitetura informativa digital (site) da RPF, se estabeleceu no decorrer dos posts pela narrativa da dinâmica da construção da Rede: as rodas de conversas, a instalação da infraestrutura, as viagens, as oficinas de formação para as comunidades envolvidas, os encontros, os apoios etc. Esses acontecimentos foram relatados por Gal Rocha e Stefania Fernandes, que assinam os posts ${ }^{13}$. Foram divulgadas matérias jornalísticas publicadas pela mídia impressa veiculadas no site na secção "Clipping". No geral, a narrativa teve um cunho jornalístico de divulgação das ações da Rede, respondendo a um padrão de informar a um público mais geral, com linguagem acessível, os andamentos dessa experiência.

Embora os posts não fossem de autoria dos Ashaninka, estavam presentes as "reverberações dialógicas" de suas vozes e de suas perspectivas sobre o processo de digitalização em curso. Assim, as vozes dos participantes deixaram seu rastro, seja discursivo, imagético ou audiovisual, expressões da dimensão de um ecossistema informativo complexo. Dos povos da floresta participantes

O complexo político econômico Ashaninka é uma trama de relações políticas xamânicas corporais e espirituais, físicas e metafísicas, internas e externas. [...] a ayahuasca é o pilar (Axis Mundi) do conhecimento xamânico amazônico; obviamente, a solidariedade mística entre a humanidade e o restante das formas naturais de vida na Amazônia indígena, passa pela amplitude da experiência extática obtida pela ingestão ritual da bebida. [...] o êxtase xamânico é, sobretudo, uma experiência de morte e ressurreição do xamã, e essa morte ritual é o signo do transbordamento da condição humana histórica à condição mítica trans-histórica."

13 A maioria dos posts é assinada por Gal Rocha, jornalista contratada pela RPF de 2006 a 2010. Em entrevista realizada com ela, via Facebook, em janeiro de 2012, Rocha afirma que havia uma equipe responsável pela comunicação do site, coordenada por Stefania Fernandes, que lia todo o material antes da publicação, com a participação de Alice Fortes, fotógrafa, e Ricardo Conte, desenvolvedor do site. Todos são do Rio de Janeiro. 
da Rede, eles eram os que participaram direta e ativamente do desenvolvimento dela, seja nas rodas de conversa para o planejamento estratégico de implantação dos Pontos de Cultura na região de abrangência da RPF, seja no encontro com os representantes de organizações governamentais e não governamentais. Tal participação é condizente com sua cosmologia xamânica e sua política interétnica.

Figura 1 - Página principal da Rede Povos da Floresta (12/11/2011)

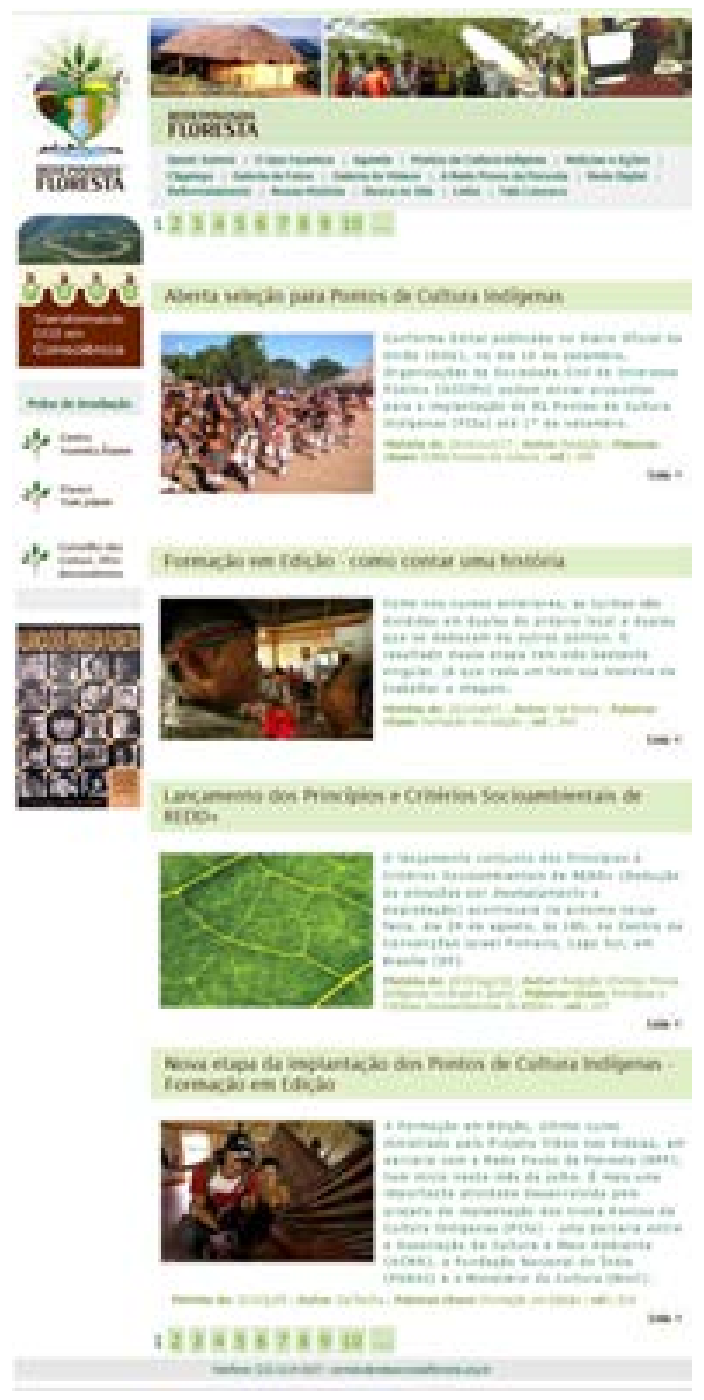

Fonte: http://www.redepovosdafloresta.org.br/ 
Na concepção da cultura Ashaninka e na arquitetura da biodiversidade da Floresta, a contaminação, a polifonia, e a heteroglossia são realidades constitutivas da complexidade do habitar ecossistêmico (Di Felice, 2009). No caso do site da Rede Povos da Floresta, a multiplicidade de vozes e contextos sociais estavam presente nos hipertextos, nas imagens, nos vídeos com os quais foram acessá-los.

\subsection{Rede Indígena de Memória e Museologia Social: a cosmopolítica da memória}

Criada em 2012, a Rede Indígena de Memória e Museologia Social é uma articulação aberta e descentralizada, protagonizada pelos povos indígenas envolvidos na luta pelo reconhecimento e preservação de suas especificidades culturais. Protagonizada pela Rede Indígena de Museus do Ceará e Pernambuco, liderados pelos povos Kanindé e Kapinawá (Gomes, 2019) e apoiados por parceiros das universidades (UFPE e Museu de Arqueologia e Etnologia da USP $)^{14}$, expressa a multiplicidade e a heterogeneidade desses espaços e das ações de memória, tradutória da potência viva da pluralidade cosmológica dos povos indígenas que resistem há mais de 500 anos no país (Viera Neto e Pereira, 2017).

As significativas experiências indígenas em processos de registro de suas memórias com o uso das tecnologias digitais, de patrimonialização, de atuação museal e de construção de espaços específicos (Cury, 2017; Gomes, 2019; Pereira, 2020) remetem ao processo de digitalização protagonizado por esses povos.

A Rede Indígena de Memória vem sendo tecida e apoiada por inúmeras organizações indigenistas, pesquisadores acadêmicos e militantes da museologia social ${ }^{15}$ que a compreendem como um instrumento fundamental de fortalecimento de ações comunitárias aliadas aos processos museais e museológicos, às lutas políticas e à reinvenção das suas tradições, sobretudo, dos povos indígenas do Nordeste.

Figura 2 - Página no Facebook da Rede

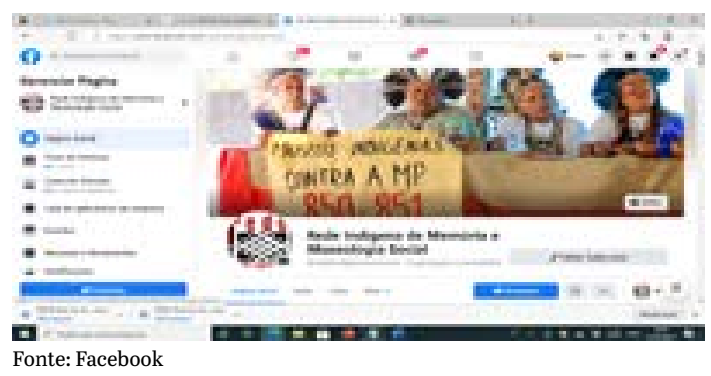

14 A tese de Gomes (2019) oferece um relato detalhado da constituição da Rede. Atualmente formada por mais de 20 etnias entre as quais, as já citadas, os Kaingangs, Pitaguary, Suruí Paiter, entre outros.

15 Consultar a lista de participantes e apoiadores da Rede em Gomes (2019) e na Página do Facebook: https:// www.facebook.com/redeindigenamemoria 
Verificou-se, portanto, durante as pesquisas que a emergente participação indígena nos museus etnográficos e o advento de espaço de memória (museus indígenas, centro de documentação e casas de cultura) (Gomes, 2019, Cury, 2017, Viera Neto \& Pereira, 2017), nascidos das demandas desses povos, indicam a preocupação desses coletivos para com a memória. Isto é, o envolvimento das comunidades indígenas em projetos de construção de espaços específicos que tratem das suas culturas por suas perspectivas, vem acompanhada de uma tomada de consciência da importância de se preservar suas narrativas, ritos, saberes e fazeres.

As iniciativas de memória promovidas por esses povos correspondem a um momento importante de reflexão coletiva sobre os processos de intensa transformação cultural que estão submetidos, desde a perda de seus elementos culturais distintivos (a língua e a prática de rituais, festas etc.) às dificuldades de transmissão dos conhecimentos dos velhos (guardiões natos dos saberes orais de seus povos) para os jovens e as crianças e a descontinuidade de práticas culturais tradicionais. Ao mesmo tempo, para os povos indígenas que já não possuem esses elementos, tais espaços coletivos se transformam num lugar fundamental de afirmação cultural.

A Rede Indígena de Memória e Museologia Social atualmente é composta por diversas iniciativas que realizam processos de patrimonialização, registro da memória e musealização distribuídas nos seguintes estados do Brasil: Acre, Amapá, Amazonas, Bahia, Ceará, Mato Grosso, Mato Grosso do Sul, Paraná, Pernambuco, Piauí, Rio de Janeiro, Rio Grande do Norte, Rondônia, São Paulo, Santa Catarina etc.

Para a construção e o fortalecimento dessa redenacional de memória, museus indígenas articulam uma série de ações tais como o mapeamento da diversidade de processos museológicos com a participação de indígenas; a articulação e compartilhamento de informações sobre as diversas iniciativas na página do Facebook e no grupo da Rede no WhatsApp. Realizam fóruns nacionais ${ }^{16} \mathrm{com}$

16 O I Fórum dos Museus Indígenas do Brasil e o III Encontro de Formação de Gestores Indígenas do Ceará aconteceram simultaneamente nos dias 16 e 17 de maio de 2015 na aldeia Fernandes, Território Indígena Kanindé (município de Aratuba, Ceará). O II Fórum Nacional de Museus Indígenas e o III Encontro de Museus Indígenas em Pernambuco ocorreram conjuntamente entre os dias 15 e 20 de agosto de 2016 na aldeia Mina Grande, localizada no Território Indígena Kapinawá (município de Buíque, PE). Além dos participantes do povo indígena Kapinawá (PE), anfitrião do encontro, estiveram presentes os povos Fulni-ô (PE), Truká (PE), Pankará (PE), Atikum (PE), Pankararu (PE), Xukuru (PE), Kambiwa (PE), Kaingang (PR, SP e RS), Potiguara (CE), Tapeba (CE), Anacé (CE), Pitaguary (CE), Jenipapo-Kanindé (CE), Tremembé (CE), Kanindé (CE), Tupinambá (BA), HuniKuin (AC), Trumai (TI Xingu/MT), Suruí Paiter (RO), Munduruku (PA), Canela-Ramkokamekrá (MA), Tabajara (PI),Kariri (PI), Potiguara de Amarelão (RN), Paiacu do Apodi (RN), Mundurucu (TO), Pataxó (BA) e Karipuna (AP); totalizando 29 povos indígenas que habitam o território brasileiro. O III Fórum Nacional de Museus Indígenas do Brasil aconteceu durante os dias 19, 20 e 21 de outubro de 2017, no povoado de Nazaré, dos povos Tabajara e Tapuio-Itamaraty do município de Lagoa de São Francisco. Participaram aproximadamente 200 indígenas representando cerca de 30 etnias oriundas de 11 estados brasileiros e um representante do Consejo Directivo da Unión de Museos Comunitarios de Oaxaca - México. O Fórum contou ainda com a participação de apoiadores e indigenistas de 17 estados brasileiros, que foram: $B A, R J, S E, P E, A P, C E, M A, M T, R R, S P, R N, P E, P I, A M, A C, R O, P B$. 
a participação de museus e iniciativas de memória indígenas, momento de reterritorialização (Deleuze e Guattari, 1995) da Rede. Implementam encontros formativos com trocas de experiências e elaboração de categorias nativas voltadas para a salvaguarda e manutenção de seus bens culturais.

Nos Fóruns, é nítida a agencialidade dos Encantados, entidades espirituais, que pela condução dos pajés por meio das rezas e cantos, por vezes, pelo transe e incorporação, participam da abertura e encerramento das atividades. Segundo Alexandre Gomes (2019, p. 182), assessor e pesquisador da Rede, esta experiência condiz com um tipo de cosmopolítica da memória designativa da "ativação de processos de rememoração, de ressignificação do passado e de construção da memória que acontecem nas interações entre diferentes sujeitos e grupos sociais, humanos e não-humanos de diferentes matizes”, envolvidos nas atividades dessas experiências de registro da memória.

Na página do Facebook da Rede, são compartilhadas as informações sobre as atividades desenvolvidas por cada uma das iniciativas, além das notícias sobre os povos indígenas. Os membros da Rede são administradores da página e, por meio da moderação, autorizam o compartilhamento dos conteúdos. No WhatsApp, participam 64, pessoas do grupo "Rede Indígena de Memória" criado em junho de 2016, em Brasília, na ocasião da oficina piloto "Memórias indígenas, museus e cultura digital"17. Nessa arquitetura interativa, o diálogo e a troca ganham uma dinamicidade ativa entre os membros participantes.

\subsection{Rede digital CineFlecha: a rede audiovisual em tempos de pandemia}

É notório que o protagonismo indígena nas redes digitais nos últimos meses está sendo ainda maior. Durante a pandemia do Covid-19 no país, agravou-se a vulnerabilidade sanitária das populações ameríndias, reverberando na atualização do genocídio com as mortes de lideranças e anciãos(ãs) detentores dos conhecimentos tradicionais. No entanto, ocasionou, ao mesmo tempo, o uso acelerado e intensivo das tecnologias digitais e ampliou-se a potência da incorporação das tecnologias de conectividade por parte dessas populações (Franco, 2020). Em diferentes plataformas (Youtube, Facebook, Instagram etc.) inúmeras atividades, encontros, debates, conversas com trocas e compartilhamento de conteúdo, organizados por indígenas e não indígenas, convergiram e ainda convergem para a conectividade, a produção intensificada de dados e para uma reflexão ameríndia sobre as suas experiências.

17 Oficina ministrada pela coautora, durante a realização da consultoria de memória indígena (entre novembro de 2015 e junho de 2016) para a Organização dos Estados Ibero-americanos (OEI) e o Instituto Brasileiro de Museus (IBRAM/MinC), no contexto do Programa Pontos de Memória, criado em 2009, como parte integrante do Programa Cultura Viva - no âmbito da parceria entre o IBRAM e a OEI, por meio do Projeto de Desenvolvimento Institucional e Técnico-Operacional para a Ampliação e Consolidação de Projetos Relacionados à Memória Social no Brasil (Prodoc OEI/BRA 08/007). A oficina voltada ao público indígena do Programa Cultura Viva buscou sensibilizá-los sobre a importância da memória como instrumento fundamental para a manutenção dos seus conhecimentos, práticas e territórios. 
Neste contexto pandêmico, foi criada em 2020 a plataforma https:// redecineflecha.org/ organizado pela Rede CineFlecha e a ASCURI (Associação Cultural de Realizadores Indígenas/MS), um convite aos povos indígenas a "compartilharem nesta plataforma suas experiências, reflexões e relatos diante da atual crise global, através de vídeos ou outras linguagens" (Plataforma Rede CineFlecha, 2021). Pretende-se, assim, criar um ambiente virtual no qual se possa juntos mirar (olhar, apontar, sonhar) novos mundos possíveis, resistir e curar.

Figura 3 - Plataforma da Rede Cine Fecha
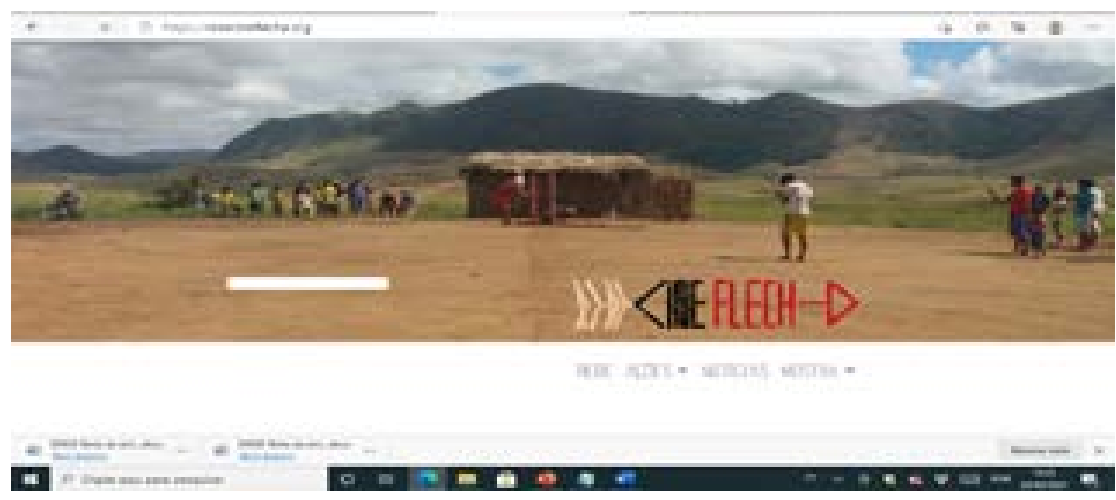

Fonte: https://redecineflecha.org/

A Rede CineFlecha é formada por coletivos indígenas e articuladores que trabalham com cinema, comunicação e antropologia. Objetiva fomentar e divulgar as produções audiovisuais de coletivos indígenas e colaboradores e conectar pessoas e coletivos de diferentes povos e lugares em torno da manifestação e criação de mundos possíveis (Plataforma Rede CineFlecha, 2021). Em especial, nas palavras de Ana Carolina Estrela da Costa, pesquisadora colaboradora da Plataforma, a Rede tem no momento, o propósito de instituir uma campanha e "reunir o máximo de vídeos produzidos por indígenas sobre como os povos indígenas estão enfrentando a pandemia" ${ }^{18}$ e disponibiliza também outros materiais audiovisuais que possam contribuir se "imaginar" outros mundos possíveis. Entre os coletivos e povos que formam a rede estão: o Pēnãhã - Coletivo de Cinema Maxakali do Pradinho (Maxakali/Tikmũ' ũn/ MG); o Coletivo Beya Xina Bena (Huni Kuin/AC); o Coletivo Akubaaj Cinta Larga de Cinema (Cinta Larga/RO); o Coletivo Ijã Mytyli de Cinema Manoki e Myky (Manoki e Myky/MT); a Associação Cultural de Realizadores Indígenas (Guarani, Kaiowá e Terena/MS); realizadores Guarani Mbya (SP/RS); entre outros.

18 Ver a divulgação da Plataforma no link disponível: https://www.youtube.com/watch?v=ASe gggo4,GY\&t=65S, acessado em 22/02/2021. 
O audiovisual entre os povos indígenas é uma poderosa mediação cultural capaz de englobar o fundamental da comunicação indígena: a oralidade e a corporalidade. As narrativas orais ganham visualidade e uma temporalidade desterritorializada, fora do tempo e do espaço da sua enunciação (Pereira, 2012).

Além disso, estamos diante de uma transformação de largo alcance não só no empoderamento desses sujeitos indígenas nos modos de se autorrepresentarem e de se apropriarem de suas próprias imagens, mas da inserção desses sujeitos "realizadores" indígenas ${ }^{19}$ - agentes produtores de novos imaginários, reconhecidos, interna e externamente, por seus trabalhos audiovisuais - na arena do conflito interétnico que não é mais a tradicional, mas a do campo da comunicação e da atuação em rede nos ambientes digitais.

\section{Conclusões}

O fenômeno global da difusão das tecnologias digitais de informação e comunicação vem sendo acompanhado por um crescente processo de digitalização das culturas locais que envolve, em um nível local e transnacional, a promoção das interações entre povos indígenas e dispositivos técnicos de acesso à internet, corroborando, assim, para a atuação ameríndia em e nas redes digitais.

Os exemplos de redes indígenas apresentados mostram uma complexidade de redes relacionais que se estende para além da dimensão sociotécnica. A singular complexidade do processo comunicativo e relacional em redes dessas populações baseia-se em algumas caraterísticas. A primeira é a qualidade da condição habitativa dos grupos, que nos casos de populações indígenas distantes dos centros urbanos e moradores da floresta, historicamente isoladas, com o processo de digitalização este lhes oferece novas possibilidades. Inserindo essas comunidades, depois de mais de quinhentos anos, na esfera pública nacional e internacional. Neste sentido, o processo de digitalização assume o significado, historicamente inédito nos contextos pós-coloniais latino-americanos, protagonizado por eles e em parceria com suas redes de relações, fomentando um processo de integração sem necessariamente a urbanização e sem a consequente perda das suas referências culturais. Esses povos conectados às redes, não restringem mais as suas relações àquelas territoriais, políticas e nacionais. Tais ações se tornam glocais, net-ativistas e portadoras da renovação da diplomacia indígena em contextos interétnicos digitais.

Um segundo importante aspecto que marca as caraterísticas e a originalidade do processo de digitalização que interessam tais populações, encontra-se na

19 "Realizador indígena" significa aquele que produz o vídeo, capta as imagens e participa do processo de edição, termo similar à "cineasta". Cabe destacar que parte da produção audiovisual dos sujeitos realizadores indígenas se submete às regras locais, ao consentimento dos velhos ou das lideranças. Desde já é um processo colaborativo adequado à estrutura social indígena. Ao mesmo tempo, a realização do vídeo se submete aos interesses e às lutas políticas internas (Carelli, 1998). 
morfologia dos tipos de redes que se formam nos âmbitos geográficos e culturais por estas habitadas. As ecologias digitais indígenas (Pereira e Di Felice, 2017) apresentam-se como uma arquitetura de rede de redes, composta por diversos níveis interconectados. De um lado a rede cosmológica e ambiental, composta por seres e entidades vivas e comunicantes, que antecedem o processo de digitalização e que constituem o universo ancestral destes povos. Por outro lado, uma rede de relações (e contatos) com organizações e coletivos que mobilizam as camadas técnicas da própria rede digital, viabilizando projetos e ações que são portadores das especificidades ecológicas desses grupos. A condição habitativa (Di Felice, 2009) destas populações, de fato, caracteriza-se por uma estrutura comunicativa de relações transpecíficas na qual cada um dos elementos envolvidos, animal, coisa ou planta, compartilham de uma humanidade em comum (Viveiros de Castro, 2013) .

Para compreender o significado e as qualidades do processo de digitalização (Pereira, 2013, Hui, 2020), que como antes explicado, interessa a quase totalidade das diversas etnias do Brasil, é fundamental situar a dimensão cultural deste populações que, de forma distinta das ecologias da pólis e do universo epistêmico e dialético ocidental (humano-técnica; humano-natureza; técnica-natureza), habitam, desde sempre, em ecossistemas reticulares e interconectados. É nesta complexidade reticular que se insere o processo de digitalização e que torna a constituição das redes sociotécnicas citadas em uma expansão do conjunto de redes já existentes.

Portanto, as redes digitais ameríndias não conectam apenas o âmbito social e relacional, mas estendem-se ao nível biológico, assumindo assim um significado que supera a simples dimensão técnica-instrumental deste processo. $\mathrm{O}$ processo de digitalização dos povos indígenas no Brasil deve ser lido não como uma intervenção externa, da tekné (Heidegger, 1977) no próprio mundo simbólico, mas como a extensão e a tradução deste em direção a uma nova linguagem audiovisual e conectiva (Pereira, 2013).

Tanto a experiência dos Ashaninkas (AC) na Rede Povos da Floresta, quanto das etnias participantes da Rede Indígena de Memória, quanto dos coletivos Maxacali (MG), Huni Huin (AC), Cinta Larga (RO), Manoki e Myky (MT), Guarani Kaiowá e Mbya e Terena (MS) da Rede CineFlecha, ainda mais no atual contexto pandêmico, nos permitiu elaborar o que chamamos de "perspectiva ecológica da comunicação digital indígena”, associadas às especificidades transespecíficas de suas cosmologias (Viveiros de Castro, 2013; Moreira, 2014) e que nos parece evidenciar a sua atuação cosmopolítica e net-ativista (Pereira, 2017, Franco, 2020) que reinscreve essas culturas no digital, em interface com as arquiteturas de interação e informação. Fenômeno indicador de uma cosmotécnica (Hui, 2020), uma incorporação nativa e local das tecnologias em direção a própria expressão da interação, do habitar (Pereira, 2013; Di Felice, 2009) e da diversidade de modos de visões e de conexão com outros mundos. 


\section{Referências bibliográficas}

Almeida, M. B. (2004). "Direitos à floresta e ambientalismo: seringueiros e suas lutas". In: Revista Brasileira de Ciências Sociais, vol. 19. n. 55. São Paulo, p. 33-53.

Amaral, A. (2009) "Autonetnografia e inserção online: o papel do pesquisador insider nas práticas comunicacionais das subculturas”. In: Revista Fronteiras-Estudos Midiáticos, vol. 11, São Leopoldo, RS, p. 14-24.

Carelli, V. (1998). Crônica de uma oficina de vídeo. São Paulo, agosto de 1998. Disponível em: http://www.videonasaldeias.org.br/2009/biblioteca.php?c=24. Acesso em: 21 fev. 2010.

Carneiro da Cunha, M. C. e Almeida, M. B. (2002). Enciclopédia da Floresta - o Alto Juruá: práticas e conhecimentos das populações. São Paulo: Companhia das Letras.

Cury, M. X. (2017). Circuitos museais para a visitação crítica: descolonização e protagonismo indígena. Revista Iberoamericana de Turismo, v. 7, p. 87-113.

Deleuze, G \& Guattari, F. (1995). Mil Platôs: Capitalismo e esquizofrenia. Vol. o1, Rio de Janeiro: Ed. 34 .

Di Felice, M. Paisagens pós-urbanas: o fim da experiência urbana e as formas comunicativas do habitar. São Paulo: Annablume, 2009.

Di Felice, M. (2017). Net-ativismo: da ação social para o ato conectivo. São Paulo: Paulus.

Di Felice, M. e PEREIRA, E. S. (orgs). (2017). Redes e ecologias comunicativas indígenas: as contribuições dos povos originários à teoria da comunicação. São Paulo: Paulus, 2017.

Floridi, L. (2014). The Fourth Revolution. How the Infosphere Is Reshaping human Reality. Oxford: Oxford University Press.

Franco, T. et tal. (2020). O net-ativismo indígena na Amazônia, em contextos pandêmicos. Estudos em Comunicação, v. 31, p. 109-131.

Franco, T. (2019). Ameríndios Conectados: As formas comunicativas de habitar e narrar o mundo, de acordo com as imagens dos modernos e dos Krahô. Tese de doutorado, Escola de Comunicações e Artes, Universidade de São Paulo (USP), São Paulo.

Gomes A. O. (2019). Museus indígenas, mobilizações étnicas e cosmopolíticas da memória: um estudo antropológico. Tese (Doutorado em Antropologia) - Universidade Federal de Pernambuco, Recife.

Granovetter, M. (1973). "The strength of weak ties”. American Journal of Sociology; vol. 78, $\mathrm{N}^{\circ}$ 6, p. 1360-1380.

Heidegger, M. (1977) Saggi e discorsi. Milano: Mursia.

Hine, C. (2000). Virtual Ethnography. London, Sage.

Hui, Y. (2020). Tecnodiversidade. São Paulo, Ubu.

Klein, T. (2013). Práticas midiáticas e redes de relação entre os Kaiowá e Guarani em Mato Grosso do sul. Dissertação (Mestrado em Antropologia Social) - Faculdade de Filosofia, Letras e Ciências Humanas, Universidade de São Paulo, São Paulo.

Kopenawa, D \& Albert, B. (2015). A queda do céu. Palavras de um xamã yanomami. São Paulo. Cia das Letras.

Kozinets, R. V (2010). Netnography: Doing Ethnographic Research Online. London, Sage.

Latour, B. (2004). Políticas da Natureza: como fazer ciência na democracia. Bauru, Edusc. . (2012). Reagregando o social: uma introdução à teoria do Ator-Rede. Salvador: Edufba, Bauru-SP: Edusc.

Lemos, A. (2010). A comunicação das coisas. São Paulo: Editora Annablume. 
Lessin, L. (2011). Nos rastros de yakuruna: a partida de Pawa e a pós- sustentabilidade Ashaninka. 2011. 204f. Tese (Doutorado em Antropologia) - Departamento em Antropologia, Universidade Estadual de São Paulo, Marília.

Mariotto, C. (2014). Produto I. Políticas Públicas de Inclusão Digital. Relatório analítico sobre o impacto dessas políticas de inclusão digital em comunidades indígenas. Brasília, Ministério das Comunicações, 2014.

Mattelart, A. e M. (2003). História das teorias da comunicação. São Paulo: Edições Loyola, 2003.

Morales, E. N. (2008). Apropriação de uma política pública de "inclusão digital" entre os Pataxós de Coroa Vermelha, Bahia. 112 f. Dissertação (Mestrado em Antropologia), Universidade de Brasília, Brasília.

Moreira, F. C. (2014). Redes xamânicas e redes digitais: por uma concepção ecológica de comunicação. 2014. 272f. Dissertação. (Mestrado em Ciências da Comunicação). Escola de Comunicações e Artes, Universidade de São Paulo.

Morin, E. (2001). Il método - la natura della natura. Milão: Raffaello Cortina Editore, 2001.

Pereira, E. S. (2012). Ciborgues indígen@s.br: a presença nativa no ciberespaço. São Paulo: Annablume.

Pereira, E. S. (2013). O local digital das culturas: as interações entre culturas, mídias digitais e território. Tese. (Doutorado em Ciências da Comunicação). Escola de Comunicações e Artes, Universidade de São Paulo.

Pereira, E. S. (2020). "Nos circuitos do Muká Mukaú - o Portal da Cultura Viva Pataxó". Cury, M. X (org,). Questões indígenas e Museus. Brodowski: ACAM Portinari, MAE-USP, p.191-202.

Pereira, E. S. (2017). Net-ativismo indígena brasileiro: notas sobre a atuação comunicativa indígena nas redes digitais. In: Di Felice, M; Pereira, E.; Roza, E. Net-ativismo: redes digitais e novas práticas de participação. Campinas, Papirus, 2017, pp. 169-182.

Pereira, E. S.; Di Felice, M. (2017). Communicative Forms of Indigenous Dwelling: The Digitalization of the Forest and Native Net-Activism in Brazil. In: Drzewiecka, J. \& Nakayama, T. Global Dialectics in Intercultural Communication - Case Studies. New York, Peter Lang.

Pimenta, J. (2007). Indigenismo e ambientalismo na Amazônia ocidental: a propósito dos Ashaninka do rio Amônia. In: Revista de Antropologia. v.5o n.2 São Paulo dez.

Renesse, N. (2012) Perspectivas indígenas sobre e na internet: ensaio regressivo sobre o uso da comunicação em grupos ameríndios do Brasil. Dissertação de mestrado. Departamento de Antropologia, Universidade de São Paulo.

Rifiotis, T. (2010) "Antropologia do ciberespaço: questões teórico-metodológicas sobre a pesquisa de campo e modelos de sociabilidade". In: Rifiotis, T, Maximo, M. E., Lacerda, J. S., Segata, J. Antropologia do ciberespaço. Florianópolis: Editora da UFSC, p. 15-27.

Robertson, R. (1992). Globalization: Social Theory and Global Culture. Sage Publications, London.

Santaella, L. (2004). Navegar no ciberespaço: o perfil cognitivo do leitor imersivo. São Paulo: Paulus.

. (2010). Ecologia pluralista da comunicação. São Paulo: Editora Paulus.

Stengers, I. (2011). Cosmopolitics II. (Posthumanities). Minneapolis: University of Minessota Press.

Sztutman, R. (2012). O profeta e o principal: a ação política ameríndia e seus personagens. 1. ed. São Paulo: Edusp. 
Vieira Neto, J. \& Pereira, E. (2017). Povos indígenas no Brasil, museus e memória: questões emergentes. In: Revista do Centro de Pesquisa e Formação do Sesc. N. 5, setembro.

Viveiros de Castro, E. (2015). Metafísicas canibais - elementos para uma antropologia pós-estrutural. São Paulo: CosacNaify, N-1 Edições. 